Revistade
Economila
Contemporâned

\title{
PROPRIEDADE E CONTROLE DOS SETORES PRIVATIZADOS NO BRASIL: UMA AVALIAÇÃO DA REESTRUTURAÇÃO SOCIETÁRIA PÓS-PRIVATIZAÇÃO
}

\author{
Marco Antonio M. da Rocha ${ }^{a}$ \\ José Maria Ferreira Jardim da Silveira ${ }^{b}$ \\ anstituto de Economia da Universidade Estadual de Campinas (IE/Unicamp). \\ 'Instituto de Economia da Universidade Estadual de Campinas (IE/Unicamp).
}

Artigo recebido em 20/08/2013 e aceito em 20/04/2015.

RESUMO: O trabalho apresenta uma análise sobre a reorganização societária ocorrida após o processo de privatização nos anos 1990, a partir da mensuração da concentração de ações com direito a voto nos principais setores privatizados. $\mathrm{O}$ artigo procura demonstrar a consolidação de certos padrões de estruturas de propriedade durante a década de 2000, que, em muitos casos, reconstituíram a participação pública. A análise foca nos setores elétrico, petroquímico, siderúrgico, de mineração, ferroviário e de telecomunicações, buscando contribuir para o entendimento das cadeias de comando formadas na reestruturação posterior à privatização sobre a infraestrutura industrial e a produção de insumos básicos no Brasil.

PALAVRAS-CHAVE: organização industrial; estrutura de capital e propriedade; infraestrutura.

CLASSIFICAÇÃO JEL: L00; G32; H54. 


\title{
OWNERSHIP AND CONTROL OF PRIVATIZED SECTORS IN BRAZIL: AN ANALYSIS OF THE OWNERSHIP RESTRUCTURING AFTER THE PRIVATIZATION PROCESS
}

\begin{abstract}
The paper presents an analysis about the ownership restructuring of the mainly privatized sectors, which follows the privatization process in Brazil. The analysis aimed to provide a measure of the concentration of direct and indirect voting rights in the companies of the electric power, petrochemicals, steel, mining, railways and telecom sectors. The paper tries to demonstrate some patterns of ownership structures that had emerged during the restructuring by the role played by state-owned institutions and pension funds.
\end{abstract}

KEYWORDS: industrial organization; ownership and control; infrastructure. 


\section{INTRODUÇÃO}

Apesar do processo de privatização estar relacionado a um conjunto concentrado de ativos de propriedade estatal vendidos ao longo da década de 1990, o aumento recente do número de concessões e parcerias público-privadas traz de volta questões propícias para uma avaliação dos resultados da grande rodada de privatização dos anos 1990, sobretudo em relação ao controle acionário sobre os ativos vendidos. Ao longo da década que se seguiu à privatização, o que se presenciou foi um profundo processo de reorganização societária, incluindo fusões, aquisições, trocas de ativos e incorporação de empresas coligadas, que definiu uma estrutura de controle com algumas características semelhantes entre os setores privatizados. A privatização também é rica em lições sobre a importância das especificidades relacionadas à governança de cada setor (Malerba, 2002), principalmente no que se refere às interações entre grupos, fontes de financiamento, dinâmica tecnológica e mecanismos regulatórios.

A venda da participação estatal nas empresas privatizadas, ao desarticular uma série de canais de coordenação entre setor público e privado ao longo da cadeia produtiva, levou também a uma revisão da maneira de fazer negócios dos setores privatizados, sobretudo quanto à exposição a um ambiente competitivo menos regulado e, geralmente, a cadeias menos integradas. Durante o Programa Nacional de Desestatização (PND), a irrelevância dada às características próprias dos arranjos setoriais no Brasil teve como resultado a formação de estruturas pouco funcionais no período imediatamente posterior à privatização, que contribuíram para a busca, por parte das empresas, de estratégias de racionalização do controle sobre os ativos adquiridos.

Ao aceitar um conjunto de títulos diversos emitidos antes do Programa Nacional de Desestatização - as "moedas da privatização" - como forma pagamento, a privatização no Brasil inseriu sócios nas empresas que não necessariamente tinham interesses de longo prazo nos setores, exceto promover os ganhos permitidos pela utilização dos títulos acumulados, o que contrasta com as características desejáveis no mundo atual de controle das corporações ${ }^{1}$. O resultado geral dos fatores apontados acima foi um forte processo de reestruturação societária, que se arrastou por pelo menos uma década. Alguns trabalhos apontam para a existência de concentração de capital - principalmente do capital votante - nos principais grupos, e também a presença de estru-

\footnotetext{
Valadares (2002b) aponta para o efeito da composição acionária prévia ao processo de privatização sobre as receitas auferidas pelos leilões, mostrando a existência de uma correlação negativa entre rendas auferidas e concentração da propriedade das empresas a serem privatizadas no período. Tem-se mais uma evidência da importância da relação entre participação societária, controle e finanças.
} 
turas piramidais, cuja explicação não parece estar relacionada à busca de "manutenção de controle ao menor custo" (Valadares, 2002a, p. 296).

$\mathrm{O}$ presente trabalho pretende analisar alguns pontos deste processo de reestruturação e avaliar quantitativamente, após cerca de duas décadas do início da privatização, quais os grupos que ao final da década passada haviam assumido o controle dos setores alvos do processo de privatização. $O$ trabalho é original não só na metodologia utilizada para consolidar as participações societárias, mas em demonstrar que há certo simplismo em tratar o processo de privatização como a mera redução da participação estatal na atividade produtiva.

O intuito é tentar demonstrar como as estruturas criadas ao longo do processo de industrialização, isto é, na constituição dos setores industriais, ainda possuem um peso significativo na escolha das formas de resolução de problemas, financiamento e coordenação interna dos setores. Entre os exemplos, pode-se citar entre os resultados do processo de reorganização societária a reconstrução de formas bipartites e tripartites de composição entre capital público e privado, nacional e/ou estrangeiro, tão típicas do processo de construção da indústria brasileira.

Algumas hipóteses de trabalho também podem ser adiantadas. Primeiramente, a existência de alguns setores privatizados em que a presença estatal se reconstruiu de forma significativa e ao longo da cadeia, o que oferece indícios de que a privatização, ao contrário de ter sido simplesmente um processo de exclusão do Estado, produziu a reorganização das formas de participação estatal na economia, associadas, geralmente, também à redução da capacidade de controle do Estado sobre os setores anteriormente comandados por este. Um segundo aspecto importante a ser discutido é a atuação histórica do Estado na criação de oportunidades de investimento e, portanto, sua influência na conformação das áreas de atuação dos grandes grupos econômicos brasileiros.

Na primeira parte deste trabalho será apresentada uma breve descrição do processo de privatização e em seguida serão expostos alguns elementos gerais do processo de reestruturação societária dos setores privatizados. Foram selecionados para o estudo os setores de energia elétrica, petroquímica, siderurgia, mineração, transporte ferroviário e telecomunicações. Estes setores, além de representarem os principais casos de privatização, ao serem analisados fornecem uma boa imagem a respeito do comando sobre a base produtiva brasileira após os anos 2000, por serem igualmente os principais setores de infraestrutura e insumos básicos.

A segunda seção e as subseções que a compõem apresentam um quadro mais detalhado do resultado da reestruturação societária dos setores estudados. Para a análise foram utilizados os dados disponibilizados pela Comissão de Valores Mobiliários (CVM), cobrindo o período de 2007-2009, e, quando possível, os dados foram com- 
pletados e verificados a partir das informações prestadas pelas próprias empresas e pelas associações empresariais. Também serão exemplificadas as principais cadeias de comando que se formaram sobre os setores privatizados.

Nas considerações finais serão abordadas algumas hipóteses sobre o sentido geral da reestruturação societária pós-privatização. Nesta seção serão discutidos os motivos que levaram a reestruturação dos setores estudados a apresentarem características semelhantes a despeito de suas diferenças técnicas. Portanto, busca-se também compreender como as singularidades de cada setor forneceu mediações para o processo de reestruturação societária. Serão apontadas igualmente algumas implicações sobre a alteração das formas de atuação estatal na economia resultante da privatização.

\section{PRIVATIZAÇÃO E REESTRUTURAÇÃO SOCIETÁRIA}

Para critérios de simplificação, pode-se dividir o processo de privatização em dois períodos. Esta divisão se justifica segundo as diferenças não só dos setores priorizados, mas também pelo arcabouço institucional que pautou a privatização. Sem contar os primeiros ensaios de privatização durante o governo Sarney, o processo de privatização apresenta duas fases de características distintas: a primeira concentrada na venda da participação estatal no setor produtivo, durante os governos Collor e Itamar Franco; e uma segunda etapa, em que o processo se concentrou nos setores de serviços e infraestrutura $^{2}$, durante o governo Fernando Henrique Cardoso.

No tocante ao segundo período houve também a criação de um ambiente institucional mais robusto que aquele presente na primeira fase. Ainda no sentido das modificações no suporte ao processo, são feitas alterações legais como o fim da distinção entre empresa nacional e estrangeira, o fim dos monopólios públicos, a criação da Lei das Concessões e de algumas agências reguladoras (Velasco Jr., 2005). Estas alterações se devem não só ao comprometimento do governo Fernando Henrique com o processo como também às necessidades criadas pela privatização de bens constitucionalmente públicos.

A diversidade dos leilões e dos consórcios formados demonstra bem a pouca atenção dada pelos diferentes governos que tocaram o processo de privatização à importância das particularidades do desenho organizacional de cada setor, o que resultou em uma corrida pelos ativos postos à venda sem uma lógica de estratégia bem defi-

\footnotetext{
2 Com a notória exceção da privatização da Companhia Vale do Rio Doce em 1997.
} 
nida. Houve, primeiramente, uma preocupação central em ocupar posições ao longo da cadeia produtiva, que, como o processo de reestruturação posterior demonstrou, nem sempre eram ativos que possuíam importância no planejamento de longo prazo dos grupos econômicos envolvidos. Contribuiu também para esta lógica a possibilidade da utilização das "moedas da privatização", que atuou como incentivo na formação de consórcios entre grandes grupos econômicos e instituições financeiras, principais acumuladores destes títulos durante a década de 1980. A troca destas "moedas" foi, sem dúvida, uma das causas que levou os setores privatizados a um longo processo de reestruturação da propriedade acionária.

Três tendências comuns podem ser destacadas na conformação do processo de reestruturação societária dos setores estudados: os descruzamentos acionários, a acelerada concentração industrial e a verticalização entre alguns setores privatizados. $\mathrm{O}$ primeiro momento após a venda das propriedades estatais caracterizou-se pela saída da maioria das empresas financeiras dos negócios adquiridos, buscando realizar o ganho obtido com o uso das "moedas" durante os leilões. Esta rodada de vendas de ativos criou uma complexa rede de propriedades cruzadas, resultado da busca das empresas em adquirir posições estratégicas que estavam sendo disponibilizadas devido à saída das empresas financeiras.

Após a saída destas empresas, o processo de reestruturação caminhou no sentido das tendências citadas acima, significando, geralmente, a redução do número de participantes e a simplificação da estrutura societária nos setores. Existem assim, três movimentos mais presentes durante o processo de reorganização setorial:

- O descruzamento acionário, isto é, as trocas de posições acionárias entre grupos como forma de obter controle exclusivo sobre certas empresas foi um movimento comum à maioria dos setores, o que resultou na simplificação da cadeia de comando sobre os ativos e na eliminação de muitos casos surgidos após a privatização de "sócios-concorrentes", isto é, de empresas que se apresentavam como sócias em empreendimentos que concorriam no mesmo segmento com outras empresas subsidiárias do mesmo grupo. Na maioria dos casos, o descruzamento foi motivado por uma procura por parte das empresas de uma melhor estrutura de controle sobre seus direitos de propriedade em relação aos ativos adquiridos.

- O processo de concentração que estas indústrias passaram em nível mundial. De modo geral, os setores intensivos em capital presenciaram um forte processo de concentração durante os anos noventa. A estrutura produtiva brasileira não ficou imune a este processo, que resultou na redução do número de participantes, através de um intenso movimento de fusões e aquisições nos setores privatizados (Miranda e Martins, 2000), significando, inclusive, em alguns casos, o 
fechamento de unidades produtivas. Este movimento também implicou, em alguns casos, o fortalecimento da participação dos grandes grupos nacionais e no abandono do setor por grupos econômicos de menor porte.

- A busca por ativos estratégicos tanto a montante como a jusante na cadeia produtiva. As principais motivações na busca por estes ativos foram os estreitamentos dos vínculos com clientes e fornecedores para a redução de custos de transação e as oportunidades de aproveitamento de economias pela diversificação correlata das atividades.

$\mathrm{Na}$ busca pelo aproveitamento de economias através da aquisição de ativos upstream e downstream, o processo de reestruturação também significou a recomposição de parte da participação estatal em termos de propriedade e controle sobre o capital total do setor - na maioria dos casos uma maior participação na propriedade do que efetivamente no controle. A hipótese que será defendida na terceira seção é a de que o porte dos grupos econômicos brasileiros frente aos seus pares estrangeiros e a peculiaridade das estruturas de financiamento de longo prazo no caso brasileiro dificilmente permitiriam a exclusão da participação estatal, principalmente no caso de setores com alta intensidade de capital. É na reorganização dos setores privatizados que há a mobilização de formas constituídas durante a trajetória de industrialização que condicionaram o padrão de estrutura societária característica do momento posterior, envolvendo grandes grupos econômicos, empresas estatais e fundos de pensão. Vale ressaltar que a metodologia adotada permite claramente observar em quais setores tal processo ocorreu ou não.

\section{REESTRUTURAÇÃO SOCIETÁRIA E CONTROLE SOBRE OS SETORES PRIVATIZADOS}

Como dito anteriormente, os diversos processos de reestruturação foram aqui estudados a partir da concentração de direitos de voto ao longo de cada cadeia produtiva. Os setores serão tratados um por um nas subseções seguintes. Para cada setor se estabeleceu um quadro com os grupos controladores mais relevantes e com a porcentagem de votos que cada um pode exercer no total da cadeia. A metodologia, portanto, não leva em conta o valor dos ativos ou o market share, e sim o acúmulo de posições acionárias, como critério de controle sobre a cadeia produtiva, isto é, como forma de avaliar a influência das decisões estratégicas de cada grupo em seu respectivo setor. Os dados apresentados nesta seção serão analisados na parte final do trabalho, na qual também serão discutidas as trajetórias de atuação de alguns grandes grupos econômicos locais a partir das oportunidades abertas pelo processo de privatização. 


\subsection{METODOLOGIA}

A metodologia apresentada abaixo permite a consolidação da participação acionária dos principais grupos econômicos nos setores. Isto é feito por meio da contabilização das diversas participações acionárias que cada empresa tem em outra, direta e indiretamente. Tomando apenas as ações ordinárias - ou seja, com direito a voto - é possível visualizar quais empresas possuem o maior comando sobre a cadeia a partir do acúmulo de posições acionárias em outras empresas. Com isto, mede-se a concentração de direitos de voto que cada grupo controlador possui no total do setor.

A metodologia utilizada foi proposta inicialmente por Baldone et al. (1997), e posteriormente incrementada com a contribuição de outros autores, sendo que a versão aqui utilizada corresponde à que é proposta por Chapelle $(2005)^{3}$. O cálculo da concentração dos direitos de voto em cada setor começa pela construção de uma matriz quadrada $\boldsymbol{A}$, tal que $\boldsymbol{A}_{n x n}=\left[a_{i j}\right]$, onde $i=1,2, \ldots, n$ e $j=1,2, \ldots, n$, em que $a_{i j}$ representa a proporção de ações que a firma $i$ possui na firma $j$, respeitando as seguintes condições:

$$
\begin{gathered}
0 \leq a_{i j} \leq 1(1) a_{i j}=0 \text { se } i=j \\
\sum_{i}^{n}=1 a_{i j} \leq 1
\end{gathered}
$$

A partir da matriz $\boldsymbol{A}$ pode-se calcular a matriz $Y$ de controle integrado, sendo $Y=\left[y_{i j}\right]$, tal que:

$$
y_{i j}=a_{i j}+\sum_{i}^{n}=1 a i j \cdot y i
$$

Em que o primeiro termo do lado direito da equação representa a proporção de controle exercido pela empresa $i$ em $j$ de forma direta e o segundo termo é a proporção de controle exercido pela empresa $i$ em $j$ de forma indireta. Transcrevendo em notação matricial, obtém-se:

$$
Y=A+Y A
$$

\footnotetext{
3 Este tipo de metodologia também apresenta alguns pontos problemáticos. Como não leva em consideração os valores dos ativos detidos, tende a sobre-estimar a importância de grupos com várias participações minoritárias e com estruturas piramidais de controle, mas de pouca importância em relação à cadeia como um todo. Este cálculo também não leva em consideração os diversos acordos entre os principais acionistas. Em suma, este tipo de análise deve ser entendido como uma proxy referente ao grau de controle exercido pelos grupos.
} 
A equação (5) representa a matriz de controle integrado, computando apenas o controle direto e indireto, da empresa $i$ em $j$. Para obtermos a matriz de controle integrado final é necessário subtrair as participações recíprocas da empresa $j$ em $i$.

$$
Y=A-D(Y) A+Y A
$$

Sendo que $D(Y)$ é a matriz diagonal em que o k-ésimo elemento é $y_{k k}$, isto é, os elementos da diagonal da matriz Y. A solução encontrada da equação (6) é:

$$
Y=\left[D(I-A)^{-1}\right]^{-1} A(I-A)^{-1}
$$

Através da matriz $Y$ pode-se obter o total de direitos de voto que cada controlador tem ao longo da cadeia produtiva direta e indiretamente.

\subsection{ENERGIA ELÉTRICA}

O setor elétrico, como alguns outros que também foram privatizados, fazia parte dos setores controlados pelas holdings estatais. O centralismo no planejamento do uso da capacidade de geração era defendido, sobretudo, pelas peculiaridades típicas de um sistema de geração baseado no uso de usinas hidroelétricas. O comando centralizado da Eletrobras sobre diversas centrais de geração de energia permitia manejar a utilização das usinas de acordo com o nível do seu reservatório e o regime pluvial a que cada uma estava sujeita.

Deste modo, o setor de energia elétrica possuía uma complexa estrutura acionária, com a Eletrobras detendo o controle sobre a geração e transmissão, e com participação nas empresas estaduais que controlavam a distribuição. No caso das empresas estaduais de distribuição, aquelas com maior mercado conseguiram diversificar suas atividades, criando ativos na geração e atuando, em alguns casos, nos serviços de utilidade pública, como água e esgoto. Logo, este modelo criava uma intrincada rede de participações acionárias, na qual a Eletrobras detinha posições acionárias indiretas nas geradoras estaduais, além das posições acionárias diretas nas suas subsidiárias de geração elétrica - CHESF, Furnas, Eletronorte, Eletrosul e a Itaipu Binacional - e nas distribuidoras estaduais; e em alguns casos extremos chegava a possuir participações indiretas nas empresas estaduais de utilidade pública. A Eletrobras ainda administrava os recursos financeiros para expansão do setor e comandava um complexo sistema de subsídios cruzados. Esta estrutura permitia que as empresas de distribuição estaduais com melhores resultados financeiros compensassem a taxa de retorno sobre os ativos das empresas estaduais com piores resultados. 
O modelo de regulação elaborado a partir da privatização e adotado em 1998 excluía a Eletrobras do controle do despacho e da administração da Rede Básica, criando o Operador Independente do Sistema (OIS, posteriormente Operador Nacional do Sistema Elétrico - ONS). O modelo de regulação de 1998 vigorou até 2004; a partir de então a estrutura de governança a que estava sujeito o setor sofreu algumas modificações, sobretudo na concepção de um planejamento do investimento em oferta mais centralizado. As modificações realizadas em 2004 restringiram também o processo de verticalização como forma de defender a concorrência no setor. A verticalização e a concentração no setor estiveram presentes desde o primeiro momento do processo de reestruturação pós-privatização, pois, em razão da forte dependência do regime pluviométrico, as incertezas às quais a geração de eletricidade está submetida criam elevados custos de transação que impulsionam as empresas a adotarem estratégias de verticalização e aquisição de ativos no mesmo segmento como forma de diversificação do risco (Santana, 2006).

Apesar das preocupações dos órgãos reguladores quanto às verticalizações e à compra de energia gerada por empresas do mesmo grupo das distribuidoras (self-dealing), tanto a verticalização como a concentração no setor parecem dificilmente evitáveis devido à natureza do sistema de geração brasileiro. Fora esta característica, o porte financeiro das empresas e instituições financeiras públicas criou um perfil de distribuição do capital no setor ainda fortemente marcado pela presença estatal e pela existência de grandes blocos acionários.

O quadro abaixo apresenta o conjunto dos grupos controladores de maior relevância.

\section{Tabela 1 - Principais controladores do setor elétrico brasileiro - 2009 (em porcentagem de direitos de voto em relação ao total do setor)}

\begin{tabular}{lc}
\hline Principais Controladores & Porcentagem \\
\hline União Federal & $8,66 \%$ \\
Banco do Brasil & $3,76 \%$ \\
Grupo Rede (DENERGE) & $3,26 \%$ \\
BNDESPar & $2,87 \%$ \\
Iberdrola Energia & $1,94 \%$ \\
Energias de Portugal - EDP & $1,85 \%$ \\
Estado do Rio Grande do Sul & $1,68 \%$ \\
Estado de Goiás & $1,38 \%$ \\
Interconexión Electrica S.A. (Colombia) & $1,33 \%$ \\
Governo do Distrito Federal & $1,26 \%$ \\
Gipar S.A. (Itacatu) & $1,23 \%$ \\
AES Holdings Brasil Ltda. & $1,22 \%$ \\
Estado de Minas Gerais & $1,08 \%$ \\
\hline
\end{tabular}


Entre os principais controladores do setor nota-se claramente a presença estatal. Além da participação da União no controle direto de empresas, há também a presença do Estado na forma de suas instituições financeiras - Banco do Brasil e BNDES - e a presença das empresas públicas estaduais. Fora a presença estatal, a participação dos grandes grupos estrangeiros no setor também é relevante, mesmo tendo, ao longo do processo de reestruturação, perdido bastante espaço.

A União Federal possui duas participações diretas relevantes no setor ${ }^{4}$ : 53,99\% das ações ordinárias da Eletrobras, associada ao BNDES Participações (BNDESPar), que possui aproximadamente $14 \%$ do capital votante, e cerca de $20 \%$ das ações ordinárias da Eletropaulo Metropolitana em associação com a AES, proprietária do restante do capital votante. Através da Eletrobras, a União Federal detém participações indiretas no sistema CEEE - geração, transmissão e distribuição - em associação com o estado do Rio Grande do Sul; na CEMAT, associada ao Grupo Rede; e na CEMAR, com a PCP Latin America. O BNDES, através de sua empresa de participações, além de participar indiretamente via Eletrobras no conjunto de empresas citadas acima e na Companhia Brasiliana de Energia (50\%) em associação com a AES, possui participações relevantes na COPEL (26,41\%), INEPAR Energia (13,33\%) e CPFL (8,44\%). Interessante notar que o BNDESPar também possui alguns blocos acionários no setor, porém, sem direito a voto, como na Rede Energia (80\%), empresa do Grupo Rede que detém controle da CEMAT, CELPA e ENERSUL.

Entre os principais grupos estrangeiros atuantes no Brasil, a Iberdrola exerce suas participações na maior parte dos casos através da Neoenergia S.A., empresa em que o grupo divide o posto de principal acionista com a Caixa Previdenciária dos Funcionários do Banco do Brasil (PREVI) e o Banco do Brasil, e que detém controle das empresas Afluente Geração e Transmissão, COELBA, COSERN e Itapebi Geração. A EDP, além de deter o controle da ESCELSA e da Bandeirante Energia, atua associada à ENDESA em alguns segmentos da cadeia produtiva através da Ampla Energia.

Este quadro demonstra bem a forma de atuação dos grupos estrangeiros no setor. Na maioria dos casos estudados, a atuação destes grupos passou a se dar em associação com as instituições públicas nacionais. Embora eles detenham normalmente a posição de sócio majoritário, o Estado atua como principal parceiro destes grupos, ajudando a diluir os riscos dos empreendimentos e compondo o montante do capital necessário. A última seção tratará especificamente destas formas típicas de associação.

\footnotetext{
4 Não foi levada em consideração, devido à dificuldade no levantamento dos dados, a participação da Petrobras no setor. Logo, pode-se dizer que a participação da União Federal no setor está ainda um pouco subestimada nos cálculos deste trabalho.
} 


\subsection{PETROQUÍMICA}

Talvez poucos setores representem tão bem as idas e vindas das diretrizes da política industrial no Brasil quanto o petroquímico. Isto se traduz nas diferentes fases de desenvolvimento do setor no Brasil, que são nitidamente marcadas pelas transformações na lógica de atuação do Estado na economia. Basta dizer que o setor foi pioneiro na instauração do modelo tripartite e na privatização da participação estatal na indústria de transformação. A principal característica da constituição do setor no Brasil foi sua concentração em torno dos polos petroquímicos, gerando uma estrutura altamente concentrada espacialmente.

Os polos, por sua vez, apresentavam uma estrutura segmentada em termos empresarias. Apesar de constituir um complexo integrado em termos do aproveitamento das economias produtivas, o polo era composto por uma série de firmas de pequeno porte reunidas em torno da central de matérias-primas, em que planta e empresa se confundem, sendo, geralmente, monoprodutoras. Em muitos casos, a situação ainda se agravava pelo fato de muitas destas empresas terem sido constituídas apenas para o aproveitamento das fronteiras de negócios criadas pelo Estado, cuja atuação no ramo petroquímico representava muitas vezes uma área distante de seu núcleo de negócios.

A estrutura de governança do setor era fortemente baseada na presença da Petrobras Química S.A. (Petroquisa). A empresa organizava os projetos de expansão, articulava as fontes de financiamento, centralizava o processo de capacitação tecnológica e geria a estrutura de propriedade e controle do setor, chegando a organizar até mesmo boa parte do comércio exterior através da Interbras - a antiga trading da estatal - durante a década de 1980. Com a saída da Petroquisa e o desinteresse das grandes empresas globais pelo mercado latino-americano, a atuação dos grupos nacionais se constituiu como o principal condicionante do processo de reorganização societária, até o retorno recente da Petrobras ao setor.

Em 1990, o PND define a retirada do Estado no setor petroquímico, com a venda das participações da Petroquisa e do BNDES nas centrais e nas empresas de segunda geração. Paralelamente, a reestruturação da indústria petroquímica mundial provocou a retirada de muitas empresas estrangeiras das joint ventures, resultando na "nacionalização" de muitas empresas de segunda geração, muitas vezes em decorrência da própria saída da empresa estrangeira daquele segmento da petroquímica (Erber e Vermulm, 1993).

O início da reestruturação apresenta duas fases com características bem marcantes, de 1994 até 1999 e de 1999 até 2002. O primeiro momento foi caracterizado pela venda dos ativos estatais, pela diminuição da participação estrangeira em razão da saída de alguns grupos (Nissho Iwai, Mitsubishi, Hoescht e Himont) e pelo desaparecimento de algumas empresas (POLISUL, CPC, $\mathrm{PPH}$ etc.). $\mathrm{O}$ resultado geral deste 
processo foi o aumento da concentração do controle de alguns grandes grupos nacionais sobre os polos petroquímicos.

O segundo período, após 1999, representou um momento de maior simplificação e descruzamento das participações acionárias e de busca por parte das empresas em adquirir o controle acionário daquelas em que já possuíam participação. O capital da OPP foi repartido em dois blocos, divididos entre os grupos Odebrecht e Unipar. A Unipar assumiu o controle integral da planta da OPP no polo de Capuava e da Poliolefinas, passando a se chamar Polietilenos União. O grupo Odebrecht assumiu o controle das unidades da OPP nos polos de Camaçari e Triunfo, ficando com o controle da COPENE (Pelai e Silveira, 2008). Mais tarde, foram unificados os ativos da Odebrecht, integrando algumas firmas e simplificando a estrutura de capital do grupo, resultando na formação da Braskem. Durante este período, o movimento de reestruturação seguiu esta lógica de simplificação da estrutura de capital da cadeia petroquímica, com a saída de mais alguns grupos estrangeiros e nacionais e a consolidação de uma grande empresa nacional.

\section{Tabela 2 - Principais controladores do setor petroquímico brasileiro - porcentagem de direitos de voto em relação ao total do setor (2009)}

\begin{tabular}{lc}
\hline Principais Controladores & Porcentagem \\
\hline União Federal & $10,54 \%$ \\
Unipar & $5,86 \%$ \\
Mossi \& Ghisolfi & $5,01 \%$ \\
Rhodia S.A. & $2,86 \%$ \\
Unigel & $2,86 \%$ \\
Itaúsa & $2,83 \%$ \\
Odebrecht S.A. & $2,26 \%$ \\
\hline
\end{tabular}

Fonte: Elaboração própria com base em dados da ABIQUIM (2009)

A partir de então, a reestruturação do setor seguiu esta lógica, ao mesmo tempo em que alguns grupos econômicos nacionais desistiram da atuação no setor. Neste sentido, pode-se citar a saída do Grupo Mariani, a absorção dos ativos do Grupo Ipiranga pela Odebrecht e pela Petrobras e a incorporação da Quattor, que reunia os ativos da Suzano Holding no setor em associação com a Unipar, pela Braskem. Em outros casos, percebeu-se também o crescimento de alguns grupos econômicos em segmentos específicos, como o Grupo Mossi \& Ghisolfi ${ }^{5}$, de origem italiana, em fibras sintéticas.

\footnotetext{
5 Apesar destes grupos não possuírem participação direta nas centrais petroquímicas, sua participação, concentrada principalmente na segunda geração, vem permitindo que se tornem empresas de destaque em alguns produtos, como é o caso do grupo Mossi \& Ghisolfi na produção de fibras sintéticas. No entanto, a estrutura tipicamente piramidal através da qual o grupo italiano exerce sua participação pode ter contribuído para a sobre-estimação de sua importância no setor.
} 
A Braskem representa bem uma das tendências pós-privatização. A trajetória da Odebrecht na petroquímica demonstrou um significativo esforço em reduzir o número de coligadas resultantes dos resultados dos leilões em uma única empresa com comando centralizado sobre os ativos. Neste caso, a associação com a Petrobras serviu para reduzir alguns custos de transação - sobretudo em relação ao fornecimento de insumos petroquímicos - e fornecer o aporte de capital necessário para acelerar o processo. A simplificação do comando sobre a estrutura de propriedade da Braskem implicou em certa subestimação do tamanho e importância da Odebrecht no setor segundo a metodologia aplicada. Apesar de controlar apenas uma única empresa, a Braskem é atualmente a maior empresa petroquímica da América Latina.

Em 2010, a Braskem anunciou a aquisição das participações societárias da Unipar na Quattor. Com isto, a Odebrecht passou a ser a segunda maior controladora do setor, sendo que, em sua totalidade, a participação da Odebrecht é dada em associação com o Governo Federal. A simplificação das estruturas de propriedade também permitiu uma maior pulverização do controle sobre as empresas de segunda geração, tendo como resultado um aumento da importância de grupos econômicos com participação em mais de uma empresa como Unigel, Itaú e a francesa Rodhia, porém, de pequeno porte em relação às grandes empresas do setor, sobretudo quando comparadas à Braskem, atualmente responsável pela maior parte da oferta interna de petroquímicos básicos.

A petroquímica brasileira fornece uma boa demonstração de como o processo de privatização seguiu no sentido de abrir espaço para o crescimento de alguns grandes grupos econômicos sem que houvesse de fato a redução da participação estatal no setor. Mesmo sendo um resultado inesperado do processo, a privatização também serviu para consolidar os direitos de propriedade sobre as centrais petroquímicas, reduzindo uma das principais fragilidades do setor no Brasil, o comando pulverizado sobre as centrais.

\subsection{SIDERURGIA}

A privatização do setor siderúrgico no Brasil coincide no tempo com um momento em que a indústria siderúrgica mundial passava também por um intenso processo de privatização. Não só um grande número de ativos do setor eram postos à venda nos países desenvolvidos, como também todo o parque siderúrgico do Leste Europeu entrava em processo de privatização. Talvez isto explique, em parte, a presença tímida dos grandes grupos internacionais na privatização brasileira e também no processo de reestruturação posterior. 
A privatização da siderurgia no Brasil se inicia com o Plano de Saneamento da Siderbrás, holding estatal do setor, em 1988. Ainda no final da década de 1980 foram privatizadas algumas usinas de menor porte - Cosim, Cimetal, Cofavi e Usiba -, arrematadas, em grande, parte pelo Grupo Gerdau (Andrade et al., 2002). O processo de desestatização toma maior vigor no início da década de 1990 com o PND, quando são privatizadas as principais usinas, entre elas a Cosinor, Acesita, CST, CSN e Cosipa. Nesta fase verifica-se a intensa participação dos fundos de pensão e outras instituições financeiras na aquisição dos ativos estatais.

Em conjunto com a venda dos ativos estatais, com o fim do controle de preços houve a desregulamentação do setor, e, posteriormente, com o processo de reestruturação produtiva das empresas houve a redução do uso de mão de obra, melhoria do mix de produtos e fechamento de algumas unidades. O processo de reestruturação produtiva atingiu também o aspecto patrimonial, verificando-se a redução do número de empresas através da sua incorporação por grupos de maior porte. A concentração seguiu a mesma lógica de melhor aproveitamento das escalas produtivas e de melhoria nas linhas de produtos e processos logísticos (Pinho e Silveira, 1998).

\section{Tabela 3 - Principais controladores do setor siderúrgico brasileiro, em porcentagem de direitos de voto em relação ao total do setor (2009)}

\begin{tabular}{lc}
\hline Principais Controladores & Porcentagem \\
\hline Grupo Gerdau & $10,77 \%$ \\
Grupo Vicunha & $7,85 \%$ \\
Grupo Votorantim & $7,27 \%$ \\
Arcelor-Mittal & $6,48 \%$ \\
NIPPON Steel & $1,49 \%$ \\
PREVI & $0,66 \%$ \\
\hline
\end{tabular}

Fonte: Elaboração própria com base em dados da CVM e IBS (2009).

Os primeiros momentos da reestruturação societária foram marcados pela saída dos principais bancos que haviam participado ativamente dos leilões de venda das participações estatais. A saída destas instituições resultou em uma intrincada rede de propriedade com diversas participações cruzadas e estruturas piramidais (Andrade et al., 2002). Posteriormente, houve o esforço no descruzamento das participações acionárias e a redução na presença dos fundos de pensão, que figuraram entre os principais grupos controladores até o início desta década. A reestruturação do setor teve também como característica o esforço dos diversos controladores no sentido de centralizar seus ativos em uma única companhia e focalizar seus negócios em áreas específicas, com a possível exceção do grupo Arcelor-Mittal, que, no Brasil, atua de forma diversificada. O grupo Gerdau, por exemplo, que detém o maior número de votos so- 
bre ativos no setor, concentrou sua participação nos leilões principalmente no segmento de aços longos, adquirindo uma série de usinas especializadas e tornando-se líder nacional no segmento.

A grande participação do grupo Vicunha deve-se à sua condição de sócio majoritário da Companhia Siderúrgica Nacional (CSN). A CSN é a principal produtora nacional de aços planos, além de possuir ativos nos setores de mineração e de transporte ferroviário. Estas, aliás, foram trajetórias de verticalização seguidas por outras empresas do setor, como será tratado nas próximas subseções. O grupo passou a ser o principal acionista da empresa em decorrência do descruzamento acionário ocorrido entre a Vale e a CSN e da aquisição de ativos da PREVI e do Bradesco Participações (BRADESPar) em 2000. Ao final da década passada, os únicos fundos de investimento que continuam a ter participação relevante no capital votante da CSN é o BNDESPar, com 4,6\%, e a Caixa Beneficente dos Funcionários da CSN, com 4,4\%.

Deve-se também chamar atenção para o fato de que muitos destes grupos detêm participações importantes em empresas siderúrgicas no restante da América Latina que não foram levados em conta nos cálculos deste trabalho. Como será tratado adiante, o processo de expansão de alguns destes grupos teve uma repercussão significativa não só na siderurgia latino-americana, como também nos setores de mineração e transporte ferroviário, implicando em uma sobreposição de alguns grupos nas principais posições de controle sobre estas indústrias.

\subsection{MINERAÇÃO}

No caso do setor de mineração optou-se por avaliar em conjunto as empresas que atuam nos segmentos de extração de ferro, manganês, bauxita, estanho, zinco, níquel e cobre. Esta opção deve-se ao fato de que além destes segmentos estarem entre os mais significativos na produção mineral brasileira, as empresas controladoras estão envolvidas na participação em mais de um destes segmentos - exceto a Alcoa, que concentra suas atividades apenas na extração de bauxita. Os demais grupos envolvidos no setor concentram suas atividades na mineração em dois ou mais segmentos através de cinco grupos: Paranapanema S.A., Vale, Votorantim Metais, Sistema Anglo American/MMX e Companhia Siderúrgica Nacional.

A concentração mundial do setor ao longo da década de 1990 - sobretudo na produção de minério de ferro e níquel - resultou na procura por jazidas competitivas globalmente, reduzindo a possibilidade de muitas empresas atuarem de forma global em vários segmentos da mineração. No caso brasileiro, a atuação das empresas visou à ampliação do seu market share nas áreas de atuação no mercado nacional através de 
uma estratégia agressiva de aquisições. No caso dos grupos estrangeiros, a estratégia de penetração no mercado brasileiro foi, na maioria dos casos, sob a forma de associação com grupos locais. Tabela 4 - Principais controladores do setor de mineração brasileiro, em
porcentagem de direitos de voto em relação ao total do setor (2009)

\begin{tabular}{lc}
\hline Principais Controladores & Porcentagem \\
\hline Grupo Votorantim & $10,04 \%$ \\
PREVI & $6,41 \%$ \\
Anglo American & $4,73 \%$ \\
Grupo Vicunha & $4,35 \%$ \\
Grupo Bradesco & $4,06 \%$ \\
Eike Fuhrken Batista & $3,97 \%$ \\
BNDESPar & $3,01 \%$ \\
ALCOA & $2,51 \%$ \\
Grupo Mitsui & $1,34 \%$ \\
\hline
\end{tabular}

Fonte: Elaboração própria com base em dados da CVM e das próprias empresas.

Em relação às áreas de atuação, no segmento de minério de ferro os principais produtores nacionais são a Vale, CSN e Anglo American/MMX. A Vale passou a ser controlada pela Valepar, holding que conta com a PREVI, BRADESPar, BNDESPar e Mitsui como principais acionistas - 58,1\%, 17,4\%, 9,5\% e 15\% do capital votante, respectivamente. Após o descruzamento acionário com a CSN, a companhia iniciou um conjunto de aquisições de posições de controle neste segmento, adquirindo o controle da Caemi Mineração e Metalurgia e da Samarco. Entre os grupos locais, a Vale é o que atua no maior número de segmentos, tendo uma participação significante na produção de minério de ferro, manganês, cobre e bauxita.

O crescimento da atuação da Companhia Siderúrgica Nacional no setor de mineração resume o motivo da forte presença do grupo Vicunha, através da Vicunha Steel S.A., no grupo de principais controladores. A CSN verticaliza a extração de ferro em Minas Gerais com a siderúrgica de Volta Redonda através da mina de ferro Casa de Pedra, controlada pela subsidiária da empresa Nacional Minérios S.A. A companhia atua também na extração e fundição de estanho através da Estanho de Rondônia S.A.

O sistema MMX/Anglo American representa o conjunto dos ativos produtivos do grupo estrangeiro no Brasil mais o sistema MMX, que se constituiu em uma associação entre o grupo e uma pessoa física (Eike F. Batista). A Anglo American, além da extração de minério de ferro, atua também em âmbito nacional na produção de níquel, através da CODEMIN, dividindo com o grupo Votorantim quase a totalidade da produção do mineral. O grupo Votorantim, por sua vez, concentrou suas atividades na produção de níquel - 49,2\% do total nacional (IBRAM, 2009) -, bauxita e zinco, sendo 
que deste último segmento possui quase o monopólio. Apesar de crescente e de grande importância entre as áreas de negócio do grupo, a elevada participação da Votorantim deve-se, sobretudo, à concentração da sua estrutura de capital em relação aos demais grupos do setor.

A Paranapanema S.A. é controlada por um consórcio de fundos de investimento, sendo controlada pela PREVI com 49,08\% das ações ordinárias. A companhia atua nas áreas de cobre, através da Caraíba Metais, e estanho, através da Mineração Taboca, subsidiária utilizada para concentrar os ativos produtivos da companhia na produção deste mineral. A holding iniciou o processo de reorganização da mineração de estanho a partir de 2004 com a incorporação da Mamoré Mineração e Metalurgia pela Mineração Taboca. De modo geral, a Paranapanema passou a adotar uma estratégia de simplificação de sua estrutura de negócios, incorporando uma série de coligadas.

O conjunto de empresas que integram os setores de mineração e siderurgia não só atuaram na aquisição de empresas do mesmo segmento, reduzindo o número de participantes destas indústrias durante a reestruturação, como também verticalizaram suas atividades, muitas vezes em direção à infraestrutura logística. Apesar da participação estrangeira significativa em alguns casos, o setor apresenta grande participação do capital nacional, inclusive em relação à participação das instituições financeiras nacionais, que atuaram ativamente das aquisições de posições acionárias no período posterior à privatização.

\subsection{FERROVIAS}

Os estudos sobre a reorganização do setor de transporte ferroviário têm seu início ainda na década de 1980 com a reestruturação da dívida da Rede Ferroviária Federal (RFFSA) e a divisão das atividades da empresa nas áreas de transporte de cargas e passageiros. A RFFSA foi incluída no PND em 1992, sob a forma de malhas ferroviárias independentes. A existência de malhas pertencentes à RFFSA sem conexão entre si, conectando-se apenas à malha de São Paulo e com tamanhos de bitola diferentes, foi a principal justificativa para a adoção desta forma de concessão.

Logo, a RFFSA foi dividida em seis malhas regionais: Malha Oeste, Centro-Leste, Sudeste, Nordeste, Sul e Ferrovia Tereza Cristina. Foi limitado a 20\% o tamanho máximo do maior bloco acionário (40\% para a Malha Nordeste), tendo como resultado a formação de consórcios amplos para a aquisição das malhas regionais. O processo de reestruturação societária envolveu basicamente a saída de algumas empresas destes consórcios e a ocupação destas posições por usuários da malha ferroviária. 
Deste modo, a reestruturação patrimonial do setor foi caracterizada pela verticalização das empresas siderúrgicas e mineradoras para a área de logística ferroviária. A falta de um marco regulatório claro sobre a concessão de serviços ferroviários nos primeiros anos pode ter motivado muitas destas empresas a adquirirem capacidade de controle sobre as malhas utilizadas, como forma de reduzir os possíveis custos de transação (Ojima e Comitre, 2008). Outro fator que pode ter contribuído para a verticalização foi a excessiva concentração da pauta de produtos transportados pelas ferrovias, sendo que somente minério de ferro e produtos siderúrgicos correspondem a cerca de $70 \%$ da carga total transportada.

A exceção deste padrão foi a America Latina Logística (ALL), empresa especializada em logística multimodal. A empresa concentrou suas aquisições consolidando sua participação nas malhas das regiões Sul, Centro-Oeste e Sudeste, integrando, assim, seus modais ferroviários no Brasil, Argentina e Uruguai (Villar \& Marchetti, 2007). A ALL foi a única empresa especializada em logística a atuar diretamente na reorganização do setor. Apesar de formada a partir de um consórcio de fundos estrangeiros, a holding ALL S.A. estabeleceu sua posição no Brasil tendo o BNDESPar como principal acionista, com $11 \%$ do capital total e cerca de $13 \%$ do votante. O fundo de participação do BNDES adquiriu os blocos acionários da PREVI e da FUNCEF durante o processo de consolidação dos ativos da companhia, que fundiu a Brasil Ferrovias S.A. com a Ferrovia Novoeste S.A. (Ernst \&Young, 2008). Com esta operação a ALL unificou o comando sobre as malhas Sul, Oeste e a malha Paulista, através da Ferrovias Bandeirantes S.A. (FERROBAN), ligando a região Centro-Oeste ao Porto de Santos.

\section{Tabela 5 - Principais controladores do setor ferroviário brasileiro, em porcentagem de direitos de voto em relação ao total do setor (2009)}

\begin{tabular}{lc}
\hline Principais Controladores & Porcentagem \\
\hline PREVI & $7,47 \%$ \\
Grupo Vicunha & $6,25 \%$ \\
Grupo Votorantim & $5,53 \%$ \\
BNDESPar & $4,90 \%$ \\
Camargo Corrêa S.A. & $2,81 \%$ \\
Estado do Paraná & $2,56 \%$ \\
Grupo Bradesco & $2,14 \%$ \\
Grupo Mitsui & $1,85 \%$ \\
Judori Participações S.A. & $1,60 \%$ \\
\hline
\end{tabular}

Fonte: Elaboração própria com base em dados da CVM e Associação Nacional de Transporte Ferroviário.

Os demais grupos controladores têm sua participação no setor ferroviário através da participação em empresas da indústria siderúrgica e mineradora. No cálculo feito neste trabalho foram incluídos todos os trechos da rede ferroviária para transporte de 
cargas, incluídos aqueles controlados pela Vale, que detém parte considerável da malha ferroviária brasileira. A companhia, além de controlar a Estrada de Ferro Carajás (EFC) e a Vitória-Minas (EFVM), possui participação na MRS Logística S.A., operadora formada por usuários da malha sudeste para exercer o controle sobre a concessão.

A MRS Logística é formada pela CSN - que, além desta participação, detém o controle da Companhia Ferroviária do Nordeste (CFN) -, Vale, USIMINAS, Gerdau e Mineração Brasileiras Reunidas, empresa controlada pela Caemi e também transferida ao controle da Vale. A MRS possui a concessão sobre o trecho mais rentável da rede ferroviária brasileira, a Malha Sudeste, e está interconectada com a Ferrovia Centro-Atlântico (responsável pela Malha Centro-Leste, atualmente também sob o controle da Vale, através do descruzamento dos ativos com a CSN e da aquisição da Mineração Tucumã), FERROBAN, EFVM e os portos de Santos, Rio de Janeiro e Sepetiba, interligando os principais centros industriais aos portos da região Sudeste.

As demais participações no setor estão ligadas a trecho menores da rede ferroviária como a Estrada de Ferro Paraná Oeste (FERROESTE) e a Estrada de Ferro Tereza Cristina. Portanto, atualmente a antiga RFFSA se encontra dividida quase totalmente entre a ALL, MRS e CFN; empresas que, em conjunto com a Vale, detêm o controle sobre a maior parte da malha ferroviária nacional. A constituição da empresa pública VALEC Engenharia, Construção e Ferrovias S.A. para a operacionalização da expansão da malha ferroviária, como os projetos das ferrovias Norte-Sul e Bahia-Oeste, por exemplo, também deve resultar no aumento da participação estatal no setor durante os próximos anos.

\subsection{TELECOMUNICAÇÕES}

A privatização dos serviços de telecomunicação foi precedida por algumas modificações no modelo adotado em relação aos outros setores. Primeiramente, a criação da agência reguladora antes dos leilões permitiu redesenhar o sistema estatal para a privatização e introduzir algumas modificações visando a promover a concorrência no setor. Outro aspecto foi o início das concessões para as empresas privadas a partir da criação da "Banda B" da telefonia celular, empresas concorrentes às criadas através do desmembramento do Sistema Telebras.

O Sistema Telebras foi dividido em doze empresas, sendo três regionais de telefonia fixa e uma operadora de longa distância, e mais oito empresas regionais de telefonia celular. Com as dez empresas concedidas com os leilões da Banda B, o setor de telecomunicações passou para o controle privado marcadamente com um número elevado de concessões. Foram adotadas ainda restrições em relação aos grupos controladores, que, no caso da Banda B, por exemplo, deveriam já ter experiência no setor e serem 
grupos nacionais (Novaes, 2000), resultando na formação de um grande número de consórcios, geralmente, contendo sócios de pequeno porte para as exigências do setor.

A divisão do Sistema Eletrobras resultou em três empresas de telefonia fixa: Telesp, Tele Norte-Leste e Tele Centro-Sul, abrangendo todas as antigas subsidiárias da Telebras, e mais a Embratel como operadora de longa distância, responsável pela interconexão entre as operadoras regionais. Foram também criadas a Telesp Celular, Tele Sudeste Celular, Telemig Celular, Tele Sul Celular, Tele Nordeste Celular, Tele Centro-Oeste Celular, Tele Norte Celular e Tele Leste Celular. Para a Banda B, as concessões foram divididas em dez áreas geográficas, agrupadas de acordo com sua atratividade. Com isto criaram-se as áreas São Paulo Capital, São Paulo Interior, Rio de Janeiro e Espírito Santo, Minas Gerais, Paraná e Santa Catarina, Rio Grande do Sul, Centro-Oeste, Amazônia, Bahia e Sergipe e a área Nordeste.

Os resultados dos leilões, contudo, não divergiram substancialmente em relação aos outros setores. Verificou-se inicialmente a entrada de algumas instituições financeiras, que após a privatização seguiram se retirando do setor; alguns grupos brasileiros, como Vicunha, Inepar, Globo e Suzano, que também participaram dos leilões, foram igualmente vendendo a maior parte de suas aquisições; e, por fim, houve a saída das grandes empresas globais produtoras de equipamentos de telecomunicação, que também estavam presentes em muitos consórcios vencedores. A forte concentração mundial no setor durante o final da década de 1990 e a rápida convergência tecnológica entre os serviços de telecomunicação podem ter contribuído para a expulsão de alguns grupos econômicos brasileiros de menor porte.

Tabela 6 - Principais controladores do setor de telecomunicações brasileiro, em porcentagem de direitos de voto em relação ao total do setor (2009)

\begin{tabular}{lc}
\hline Principais Controladores & Porcentagem \\
\hline TELMEX & $4,37 \%$ \\
Telefónica Internacional S.A. & $3,86 \%$ \\
América Móvil Telecom & $3,66 \%$ \\
BNDESPar & $3,44 \%$ \\
Portugal Telecom & $3,20 \%$ \\
Grupo Globo & $3,04 \%$ \\
Grupo Telecom Itália & $2,84 \%$ \\
PREVI & $2,09 \%$ \\
\hline
\end{tabular}

Fonte: Elaboração própria com base em dados da CVM.

Justamente devido à crescente convergência tecnológica dos serviços de telecomunicação, foram contemplados neste estudo não só a telefonia fixa e celular como também o provimento de internet de banda larga e televisão a cabo, serviços incipientes na época da privatização. Estes serviços são liderados no Brasil por uma associação entre o 
Grupo Globo e a TELMEX. A empresa mexicana se consolidou como líder dos serviços de telecomunicação no Brasil. Como a América Móvil, criada em 2000 a partir de uma divisão dos ativos da TELMEX, também é uma empresa associada ao mesmo grupo controlador mexicano, e os dados demonstram a clara liderança mexicana neste setor.

Entre os principais acionistas, o grupo mexicano atuava no controle das empresas Americel S.A. ("Claro”) e Embratel nos serviços de telefonia, e conjuntamente com o grupo Globo, é um dos sócios majoritários da NET Serviços de Comunicação S.A., empresa de serviços de internet de banda larga, televisão a cabo e telefonia fixa. A Telefónica, empresa espanhola, atua no setor em telefonia fixa, através da própria marca (assumindo a concessão da antiga Telesp), na internet de banda larga e na telefonia celular, através da marca Vivo, controlada pela Brasilcel, joint venture da empresa com a Portugal Telecom. O BNDESPar, a partir da recente movimentação patrimonial no setor, assumiu o controle da Telemar Participações, e, portanto, indiretamente da Brasil Telecom, responsáveis pelas prestadoras de telefonia Telemar e Oi. E, por fim, o grupo Telecom Itália controla a Tim Brasil, prestadora de serviços de telefonia móvel.

Não obstante, existem conjuntos relevantes de acionistas importantes que atuam sem deter o controle das empresas, como é o caso da PREVI, Inepar, Andrade Gutierrez e outros fundos de investimentos que atuam no setor. As estruturas de controle das empresas de telecomunicações no Brasil são, na maioria dos casos, particularmente pulverizadas quando comparadas ao restante das empresas brasileiras, resultando em um baixo grau de concentração dos direitos de voto quando comparado aos outros setores aqui estudados, apesar do alto grau de oligopolização em termos de prestadoras de serviços.

\section{CONSIDERAÇÕES FINAIS}

A partir dos principais grupos controladores formados durante a última década, podem-se analisar algumas preocupações tidas quanto aos efeitos da privatização sobre a estrutura industrial brasileira. Primeiramente, entre os principais grupos econômicos, somente em telecomunicações há a visível predominância dos grupos estrangeiros no controle. Em outro setor, energia elétrica, os grupos estrangeiros têm ampla atuação, porém, geralmente em associação com um grupo nacional ou empresa estatal, e sem exercer liderança no setor. Nos outros setores - petroquímica, siderurgia, mineração e transporte ferroviário - observou-se a presença de grupos econômicos nacionais de forma significativa. Portanto, apesar do aumento da participação estrangeira em todos os setores - exceto petroquímica -, apenas em telecomunicações se pode falar que houve de fato uma desnacionalização do setor. Mesmo no setor elétrico, no qual a re- 
estruturação societária inseriu formas bipartites de associação entre capital estatal e estrangeiro, a participação estatal ainda é elevada e ocorre de forma bem mais ampla do que a de qualquer outro grupo estrangeiro ou brasileiro.

Sobre a liderança que o setor financeiro internacional poderia assumir sobre os setores privatizados no Brasil, também não houve muito interesse pela manutenção dos ativos adquiridos, resultando posteriormente na venda da maioria das participações que os grupos financeiros estrangeiros adquiriram nos leilões, com exceção de algumas participações importantes em grandes empresas nacionais. As instituições financeiras privadas brasileiras, com exceção do Bradesco, também não se associaram ao setor produtivo de forma significativa, como poderia ter ocorrido em virtude da utilização das "moedas da privatização"; pelo contrário, os fundos de pensão controlados pelos sindicatos, as empresas públicas e o BNDES foram se tornando os principais protagonistas do processo de reorganização setorial.

Após a saída de um primeiro grupo de empresas dos consórcios formados para a privatização, criou-se uma série de oportunidades para que os grupos econômicos locais ocupassem posições estratégicas, que foram, em geral, aproveitadas através do recurso à composição de sociedades com instituições públicas e/ou com fundos de pensão. A corrida por estes ativos por parte dos grupos nacionais motivou a busca por parcerias com instituições de maior volume financeiro para o suporte à continuidade da consolidação da estrutura de controle sobre os ativos estratégicos setoriais. Neste sentido, as características particulares do sistema financeiro brasileiro e a atuação das empresas públicas auxiliaram na definição dos principais acionistas resultantes da reestruturação societária, tendo como resultado a formação de estruturas de propriedade caracterizadas pela regularidade da participação estatal e dos fundos de pensão como sócios nas holdings formadas.

Ademais, verificou-se que as empresas visivelmente procuraram simplificar as estruturas societárias resultantes do processo de privatização, o que demonstra a preocupação por parte destas em assegurar um controle mais efetivo sobre os ativos considerados estratégicos. Deste modo, a privatização consolidou a posição de liderança de certos grupos econômicos nacionais sobre alguns dos setores estudados. Nos setores de petroquímica e energia elétrica a presença estatal se demonstrou dificilmente substituível em virtude do volume dos investimentos envolvidos e das peculiaridades da organização destes setores no caso brasileiro. Mas, de modo geral, consolidado o processo de reestruturação, os grandes grupos nacionais racionalizaram a estrutura de controle sobre seus ativos em grandes holdings setoriais (Hiratuka e Rocha, 2015)

$\mathrm{O}$ intuito deste trabalho foi, portanto, fornecer alguns dados concretos sobre as articulações industriais criadas após a privatização, supondo que o conhecimento destas articulações é um ponto de partida importante para a formulação de políticas in- 
dustriais mais efetivas, principalmente no sentido de apontar as possibilidades de atuação da política industrial através dos canais instituídos a partir da privatização. Neste sentido, a recorrência do padrão de organização societária - grandes grupos nacionais, fundos de pensão e empresas públicas - em outros projetos públicos de investimento e concessões demonstra a relevância do estudo dos padrões societários formados a partir da privatização; sobretudo, levando em consideração a forma como este padrão vem se disseminando em alguns grandes projetos de investimento público/ privado no período mais recente.

\section{REFERÊNCIAS}

ASSOCIAÇÃO BRASILEIRA DA INDÚSTRIA QUÍMICA (ABIQUIM). Guia da Indústria Química Brasileira. São Paulo: ABIQUIM, 2009.

ANÁLISE. Anuário 2009: Análise Energia. Revista, 2009.

ANDRADE, M. L; CUNHA, L. M.; GANDRA, G. Reestruturação na Siderurgia Brasileira. Boletim BNDES, Rio de Janeiro: BNDES, 2002.

BALDONE, S.; BRIOSCHI, F.; PALEARI, S. Ownership measures among firms connected by cross-shareholdings and a futher analogy with input-output theory. Milão: Politecnico di Milano, 1997, mimeo.

CHAPELLE, A. Separation between ownership and control: where do we stand? Corporate Ownership \& Control, v. 2, n. 2, p.91-101, 2005.

ERBER, F.; VERMULM, R. Ajuste estrutural e estratégias empresariais. Rio de Janeiro: IPEA, 1993.

ERNST \& YOUNG. ALL - America Latina Logistica S.A. and its subsidiaries. Relatório Financeiro. ERNST \& Young, 2008, mimeo.

HIRATUKA, C.; ROCHA, M. A. Grandes grupos no Brasil: estratégias e desempenho nos anos 2000. Texto de Discussão, IPEA, Rio de Janeiro, n. 2049, 2015.

INSTITUTO BRASILEIRO DE MINERAÇÃO (IBRAM). Panorama Mineral Brasileiro. [On-line] IBRAM, 2009. Disponível em: <http://www.ibram.org.br/>. Acesso em: 20 ago. 2013.

IBS. Anuário Estatístico. São Paulo: IBS, 2009.

MIRANDA, J. C.; MARTINS, L. Fusões e Aquisições de empresas no Brasil. Economia e Sociedade, n. 14, p. $67-88,2000$.

NOVAES, A. "Privatização do setor de telecomunicações no Brasil”. In: PINHEIRO, A.; FUKASAKU, K. (Eds.) A privatização no Brasil: o caso dos serviços de utilidade pública. Rio de Janeiro: BNDES, 2000.

OJIMA, A.; COMITRE, V. O setor ferroviário sob a perspectiva da economia dos custos de transação: a experiência do transporte de algumas commodities do agronegócio. In: Con- 
gresso da Sociedade Brasileira de Economia, Administração e Sociologia Rural, 66, Rio Branco, AC, 2008, mimeo.

PELAI, F.; SILVEIRA, J. M. Análise do processo de reorganização societária de grupos que atuam na indústria petroquímica brasileira. In: Encontro Nacional de Economia, 36, Salvador, BA. Anais... Salvador: ANPEC, 2008, Vol. 1.

PINHO, M.; SILVEIRA, J. M. Os efeitos da privatização sobre a estrutura industrial da siderurgia brasileira. Economia e Sociedade, n. 10, p. 81-109, 1998.

ROCHA, M. A. Estrutura de capital e sistemas nacionais de governança: um estudo a partir da privatização do setor petroquímico brasileiro. Dissertação de Mestrado, Instituto de Economia, Universidade Estadual de Campinas, 2009.

SANTANA, E. Economia dos custos de transação, direito de propriedade e a conduta das empresas no setor elétrico brasileiro. In: Encontro Nacional de Economia, 34, Vitória, ES, 2006. Disponível em: <http://www.anpec.org.br/encontro2006/artigos/A06A065.pdf>. Acesso em: 20 ago. 2013.

VALADARES, S. "Estrutura de controle e propriedade de empresas brasileiras". In: BONOMO, M. (Org.) Finanças aplicadas ao Brasil. Rio de Janeiro: FGV, 2002a.

VALADARES, S. "Efeito da composição acionária sobre o resultado de um leilão de privatização: análise do caso brasileiro”. In: BONOMO, M. (Org.) Finanças aplicadas ao Brasil. Rio de Janeiro: FGV, 2002b.

VELASCO JR., L. A política pública de privatização no presidencialismo de coalizão brasileiro. Tese de Doutorado, Instituto Universitário de Pesquisas do Rio de Janeiro, 2005.

VILLAR, L.; MARCHETTI, D. "Dimensionamento do potencial de investimentos do setor ferroviário”. In: TORRES FILHO, E.; PUGA, F. Perspectivas do investimento 2007/2010. Rio de Janeiro: BNDES, 2007. 